\title{
Placental infiltration of inflammatory markers in gestational diabetic women
}

\author{
Ines Mrizak ${ }^{1,2}$, Oussama Grissa ${ }^{1,2}$, Benoit Henault ${ }^{1}$, Mariem Fekih ${ }^{4}$, Ali Bouslema ${ }^{3}$, Imen \\ Boumaiza $^{3}$, Monia Zaouali², Zouhair Tabka ${ }^{2}$ and Naim A. Khan ${ }^{1}$ \\ ${ }^{1}$ University of Burgundy, INSERM U866, Faculty of Life Sciences, Dijon, France \\ ${ }^{2}$ Department of Physiology and Functional Exploration, Farhat Hached University Hospital, Sousse, Tunisia \\ ${ }^{3}$ Department of Biochemistry, Sahloul University Hospital, Sousse, Tunisia \\ ${ }^{4}$ Department of Gynecology, Farhat Hached University Hospital, Sousse, Tunisia
}

\begin{abstract}
Gestational diabetes mellitus (GDM) is pathology of glucose intolerance during pregnancy. It is influenced by maternal hyperglycemia and insulinemia through placental circulation. The study was undertaken to investigate the implication of pro-inflammatory factors in the placenta of GDM women. Thirty GDM women have delivered macrosomic babies, and 30 healthy age-matched pregnant women have delivered non macrosomic babies, were recruited in the study. The mRNAs encoding for IL-6, TLR4, TGF- $\beta$, CD68, CD14, EMR-1, CCL2, TCR- $\alpha$, T-bet, GATA-3, leptin and adiponectin were quantified in placental samples by using RT-qPCR. The mRNA expression of the pro-inflammatory factors, i.e., IL-6, TLR4 and TGF- $\beta$, was increased in GDM placenta. The mRNA expression of markers of infiltration of macrophage, i.e., CD68, CD14 and EMR-1, was higher in the GDM placenta than the control placenta. The expression of mRNA of TCR- $\alpha$, an indicator of T-cell infiltration, was significantly higher in the GDM placenta. Interestingly, the expression of mRNA of GATA-3, an indicator of Th2 phenotype differentiation, was unregulated in the GDM placenta. Leptin and adiponectin mRNAs were also significantly increased in the placenta of the GDM group. Our results revealed that there is an increase of inflammation in the GDM placenta which might be involved, in part, in the pathogenesis of macrosomia.
\end{abstract}

\begin{abstract}
Abbreviations: BMI, body mass index; HC, head circumference; CCL, chemokine ligand; CRP, C-reactive protein; EMR-1, mucin-like hormone receptor; FGF, fibroblast growth factor; GDM, gestational diabetes mellitus; HbA1c, glycated hemoglobin A1c; HDL, high density lipoprotein; IGF, insulin growth factor; IL, interleukin; INF, interferon; LDL, low density lipoprotein; RT-qPCR, real time quantitative polymerase chain reaction; TCR, T-cell receptor; TGF- $\beta$, transforming growth factor; Th1/Th2, T helper type 1/type 2; TLR, toll-like receptor; TNF, tumor necrosis factor.
\end{abstract}

Key words: Gestational diabetes mellitus — Macrosomia — Inflammation — Placenta

\section{Introduction}

Gestational diabetes mellitus (GDM) is a state of glucose intolerance which disappears shortly after delivery (Torloni et al. 2009), but might cause some complications to mother and, the newborn babies are born with an increased incidence of

Correspondence to: Ines Mrizak, Department of Physiology and Functional Exploration, Farhat Hached University Hospital, Rue Mohamed Karoui, 4002, Sousse, Tunisia

E-mail: ines.mrizak@hotmail.com neonatal obesity, i.e., macrosomia (Wroblewska-Seniuk et al. 2009). Macrosomic babies have increased rates of birth trauma, shoulder dystocia, respiratory distress syndrome and cesarean delivery (Galtier et al. 2008; Yogev and Catalano 2009).

Macrososmic infants are also at increase risk for obesity in adulthood (30\% overweight in adolescence), glucose intolerance and type 2 diabetes (Bellamy et al. 2009; Wroblewska-Seniuk et al. 2009). It should be noted that the GDM mothers are also at risk of developing another GDM during subsequent pregnancies with a probability of 30 to $84 \%$ (Kim et al. 2007; Reece et al. 2009). These mothers are predisposed 
to develop metabolic syndrome by $60 \%$ (Krishnaveni et al. 2007) or type 2 diabetes with an incidence of $37 \%$. The prevalence of GDM is 3.5 times higher in these women than those in a normal pregnancy (Lee et al. 2008).

In GDM, the placenta is the target of the maternal hyperinsulinemia and insulin-like growth factor 1 (IGF-1) (Handwerger et al. 2000), involved in the increased transport of amino acids and glucose to the fetus (Kniss et al. 1994). Indeed, the number of placental receptors for insulin and IGF-1 increases very significantly in GDM women (Bhaumick et al. 1988). We have also demonstrated in a previous study that growth factors might be implicated in GDM and, in part, in the pathology of macrosomia via the maternofoeto-placental axis (Grissa et al. 2010).

In a study conducted on animals, an increase in pro-inflammatory cytokines like IFN- $\gamma$ and IL- 2 has been reported. Moreover, in macrosomic infants, the ratio of IFN- $\gamma / \mathrm{IL}-4$ is increased by 21 -fold as compared to controls, suggesting the differentiation of Th 0 cells to Th 1 cells, the pro-inflammatory phenotype (Atègbo et al. 2006; Khan et al. 2006). All of these observations suggest that there exists a strong link between inflammation, GDM and macrosomia.

As regards adipokines, Uzelac et al. (2010) have suggested that the GDM placenta contributes to elevated leptin levels due to a decrease in the conversion of testosterone to estrogens and to an increase in the production of leptin. Hence, androgen and leptin signaling pathways may be over-activated by the presence of excessive ligands and over-expressed receptors in a GDM placenta.

Keeping in view the above mentioned arguments, it was worthwhile to study the inflammatory status of GDM placenta. During inflammation, T-lymphocytes may infiltrate the placenta; therefore, we investigated mRNA expression of TCR- $\alpha$ to reveal T-cell infiltration. CCL2 is a chemokine that possesses attractive properties for monocytes but not for neutrophils. Hence, we also detected mRNA encoding for CCL2. T-cells differentiate, principally, either to Th1 or Th2 phenotypes (Khan et al. 2006). Therefore, we detected the presence of transcriptional factors like T-bet for Th1-cells and GATA-3 for Th2-cells in the placenta. We also identified the expression of mRNA encoding for leptin (pro-inflammatory chemokine) and adiponectin (anti-inflammatory chemokine) which may play a key role in the balance of inflammation and pathogenesis of GDM (Bajoria et al. 2002; Meller et al. 2006).

\section{Materials and Methods}

\section{Patients}

The subjects were recruited form the Gynecology Department of Farhat Hached University Hospital Sousse (Tunisia) between June 2011 and December 2011. The study protocol was approved by Farhat Hached Hospital Ethical Committee for Research on Humans in Tunisia.

An informative written consent was signed by all the subjects of the study. The pregnant women were from 17 to 42 years old.

Placenta was collected from 60 deliveries divided into 30 GDM pregnancies and 30 control pregnancies.

The control women were selected as pregnancies without any history of illness, with no related complications and no risk factor of gestational diabetes including normal glucose tolerance tested every trimester of pregnancy. The women had no history of smoking and they were not taking any medicine that could influence the modulation of the GDM. The GDM was diagnosed by O'ssulivan test during pregnancy. None of GDM mothers were treated with insulin.

\section{Anthropometric parameters}

The body mass index (BMI) was calculated as body mass divided by the square of the height. The BMI for control women was $23.15 \pm 2.3 \mathrm{~kg} / \mathrm{m}^{2}$ and for GDM women, it was $24.9 \pm 2.9 \mathrm{~kg} / \mathrm{m}^{2}$.

\section{Blood sample collection}

The blood was collected from GDM and control women through the arm vein. Cord blood sample was obtained from the umbilical vein immediately after delivery.

Fasting venous blood samples were collected in tubes containing EDTA or lithium heparinate to obtain, respectively, plasma or serum. Plasma was immediately used for determination of glucose. HbAlc was determined in total blood with EDTA. The serum was aliquoted and conserved at $-80^{\circ} \mathrm{C}$ for the determination of other biochemical parameters.

\section{Determinations of plasma biochemical parameters}

Serum was used for the determination of insulinemia by ELISA (Peprotech Paris, France). Lipid levels were determined by an enzymatic method including total cholesterol, triglyceride (TG), high density lipoprotein (HDL) and low density lipoprotein (LDL), (Boehringer Mannheim, Germany). Plasma fasting glucose was analyzed by oxidase method (Beckman instruments, Fullerton, CA, USA). Plasma levels of apolipoprotein A1 and $\mathrm{B}$ were determined by spectrophotometry. $\mathrm{C}$ reactive protein (CRP), uric acid, proteins, aspartate aminotransferase and alanine aminotransferase were analyzed at the Biochemistry Department of Sahloul University Hospital (Sousse, Tunisia). 
Detection of mRNA of inflammatory factors by quantitative RT-PCR

Using RT-qPCR, we determined mRNA expression of IL-6, toll-like receptor 4 (TLR4), transforming growth factor $\beta$ (TGF- $\beta$ ), CD68, CD14, EMR-1, chemokine CCL2, T-cell receptor $\alpha$ (TCR- $\alpha)$, T-bet, GATA-3, leptin and adiponectin.

Total RNA was extracted from placental tissue by using Trizol (Invitrogen). Quantity of mRNA extracted was evaluated by measuring OD at $260 \mathrm{~nm}$ and $280 \mathrm{~nm}$. An agarose-gel electrophoresis was done for every extract in order to verify the integrity of purified mRNA.

One $\mu \mathrm{g}$ of total mRNA was reverse transcribed with $\mathrm{Su}$ per script II RNAse H-reverse transcriptase. RT-PCR was performed on the iCycler iQ real time detection system and amplification was undertaken by using SYBER Green I detection. Oligonucleotide primers, used for mRNA analysis, were based on the sequences of human genes in Human Gene Database (PubMed web site). The sequences of PCR primers used are presented in Table 1.

Relative quantification of mRNA in different groups was determined as follows: $\Delta \Delta \mathrm{Ct}=\Delta \mathrm{Ct}$ (gene of interest) $-\Delta \mathrm{Ct}$ (18S), where $\Delta \mathrm{Ct}=\mathrm{Ct}$ (macrosomic) $-\mathrm{Ct}$ (control). Relative

Table 1. Amplified genes and their corresponding primer sequences used for real-time quantitative PCR

\begin{tabular}{|c|c|}
\hline $\begin{array}{l}\text { Genes } \\
\text { amplified }\end{array}$ & Primer sequences \\
\hline IL-6 & $\begin{array}{l}\text { forward, 5'-TCTCCACAAGCGCCTTCG-3' } \\
\text { reverse, 5'-CTCAGGGCTGAGATGCCG-3' }\end{array}$ \\
\hline TLR4 & $\begin{array}{l}\text { forward, 5'-TCAGAAACTGCTCGGTCAGA-3' } \\
\text { reverse, 5'-ATTAGGAACCACCTCCACGC-3' }\end{array}$ \\
\hline TGF- $\beta$ & $\begin{array}{l}\text { forward, 5'-GCTGTACATTGACTTCCGCA-3' } \\
\text { reverse, 5'-GTCCAGGCTCCAAATGTAGG-3' }\end{array}$ \\
\hline CD68 & $\begin{array}{l}\text { forward, 5'-CACCTGCTTCTCTCATTCCC-3' } \\
\text { reverse, 5'-TTGTACTCCACCGCCATGTA-3' }\end{array}$ \\
\hline CD14 & $\begin{array}{l}\text { forward, 5'-CTGCAACTTCTCCGAACCTC-3' } \\
\text { reverse, 5'-CCAGTAGCTGAGCAGGAACC-3' }\end{array}$ \\
\hline EMR-1 & $\begin{array}{l}\text { forward, 5'-GGGCAGAGACTACAAGCCAG-3' } \\
\text { reverse 5'-GACATCCTCTAGGCCATCCA-3' }\end{array}$ \\
\hline CCL2 & $\begin{array}{l}\text { forward, CCCCAGTCACCTGCTGTTAT-3' } \\
\text { reverse, 5'-GCTTCTTTGGGACACTTGCT-3' }\end{array}$ \\
\hline TCRa & $\begin{array}{l}\text { forward, 5'-AGAAGGCAGTCTTGTGGGTG-3' } \\
\text { reverse, 5'-CAGAGAAGGAAAGGGTGTGC-3 }\end{array}$ \\
\hline T-bet & $\begin{array}{l}\text { forward, 5'-TGTCCTACTACCGAGGCCAG-3' } \\
\text { reverse, 5'-ATCTCAGTCCACACCAAGGG-3' }\end{array}$ \\
\hline GATA-3 & $\begin{array}{l}\text { forward, 5'-CCTACGTGCCCGAGTACAG-3' } \\
\text { reverse, AGTTCACACACTCCCTGCCT-3' }\end{array}$ \\
\hline Leptin & $\begin{array}{l}\text { forward, 5'-GGCTTTGGCCCTATCTTTTC-3' } \\
\text { reverse, 5'-CCAAACCGGTGACTTTCTGT-3' }\end{array}$ \\
\hline Adiponectin & $\begin{array}{l}\text { forward, 5'-CCTAAGGGAGACATCGGTGA-3' } \\
\text { reverse, 5'-GTAAAGCGAATGGGCATGTT-3' }\end{array}$ \\
\hline
\end{tabular}

quantity was collected as follows $\mathrm{RQ}=(1+\mathrm{E})^{-\Delta \Delta \mathrm{Ct}}(\mathrm{Ct}$, cycle threshold; R, report of DNA quantity; Q, DNA quantity; E, reaction efficiency).

\section{Statistical analysis}

All results were expressed as mean \pm standard deviation (SD). Statistical significance of the differences between groups was performed by LSD test. $p$ levels retained for significance was $p<0.05$. We used Statistica, version 6.0 (Statsoft, Tulsa OK USA) for statistical calculations.

\section{Results}

\section{Blood HbA1c, insulin and glucose levels}

GDM women exhibited higher fasting glycemia and insulinemia compared to the control pregnant women. Plasma $\mathrm{HbA1c}$ levels were statistically higher than the control mothers (Table 2).

\section{Serum biochemical parameters}

There is no difference between the two groups of mothers with regards to HDL, LDL and total cholesterol but TG levels were higher with the GDM mothers (Table 2). Levels of Apo lipoprotein A1, B and CRP remained unchanged in GDM women, compared to the control group. Uric acid levels increased in GDM mothers, but serum proteins and alanine aminotransferase were decreased in this group, compared to the control group (Table 2).

Table 2. Biochemical characteristics of mothers

\begin{tabular}{lcc}
\hline & Controls & \multicolumn{1}{c}{ Diabetic } \\
\hline Insulinemia $(\mu \mathrm{UI} / \mathrm{ml})$ & $4.99 \pm 1.20$ & $10.55 \pm 4.80^{\star *}$ \\
HbA1c $(\%)$ & $4 \pm 0.50$ & $6.9 \pm 0.45^{\star *}$ \\
Fasting glucose $(\mathrm{mmol} / \mathrm{l})$ & $4.57 \pm 0.77$ & $6.80 \pm 0.66^{\star *}$ \\
Apolipoprotein $\mathrm{A} 1(\mathrm{~g} / \mathrm{l})$ & $2.01 \pm 0.29$ & $1.91 \pm 0.26$ \\
Apolipoprotein B $(\mathrm{g} / \mathrm{l})$ & $1.31 \pm 0.25$ & $1.23 \pm 0.09$ \\
CRP $(\mathrm{mg} / \mathrm{dl})$ & $4.60 \pm 0.8$ & $5.75 \pm 1.42$ \\
Total cholesterol $(\mathrm{mmol} / \mathrm{l})$ & $5.74 \pm 0.21$ & $5.19 \pm 0.32$ \\
HDL-cholesterol $(\mathrm{mmol} / \mathrm{l})$ & $2.25 \pm 0.16$ & $2.20 \pm 0.12$ \\
LDL-cholesterol $(\mathrm{mmol} / \mathrm{l})$ & $2.61 \pm 0.26$ & $2.16 \pm 0.26$ \\
Triglycerides $(\mathrm{mmol} / \mathrm{l})$ & $1.92 \pm 0.14$ & $2.48 \pm 0.15^{\star}$ \\
Uric acid $(\mu \mathrm{mol} / \mathrm{l})$ & $257.92 \pm 15.66$ & $326 \pm 29.39$ \\
Proteins & $58.60 \pm 0.95$ & $55.5 \pm 1.44^{\star *}$ \\
Aspartate aminotransferase (UI/l) & $30.02 \pm 4.19$ & $21.23 \pm 2.57$ \\
Alanine aminotransferase $(\mathrm{UI} / \mathrm{l})$ & $16.45 \pm 2.5$ & $8.25 \pm 1.49^{* *}$ \\
\hline Values are means
\end{tabular}

Values are means \pm SD. $n=30$ for both groups (control and gestational diabetic mothers). Significant difference: ${ }^{\star} p<0.05$, ${ }_{* *} p<0.001$ vs. Controls. 


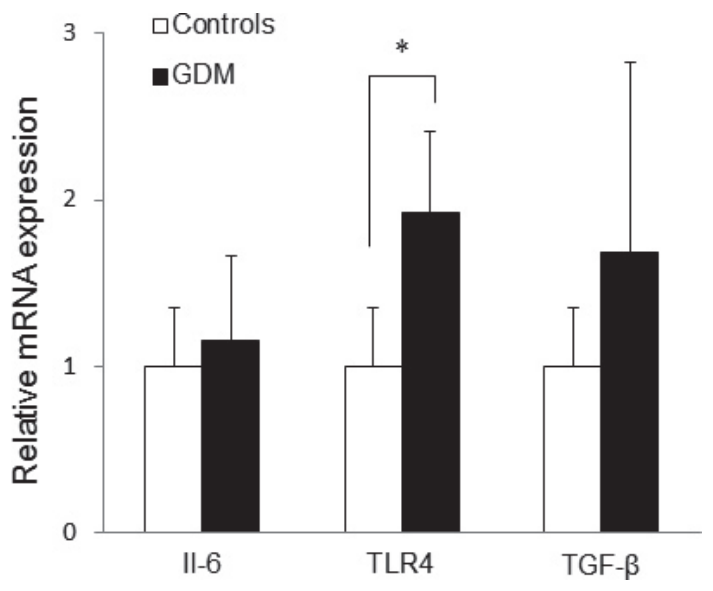

Figure 1. IL-6, TLR- 4 and TGF- $\beta$ mRNA expression in GDM placenta in comparison to control group. mRNA expression by RT-qPCR was assessed as described in Materials and Methods. $n=60$ gestational diabetic mothers and macrosomic babies, ${ }^{*} p<0.05$. IL, interleukin; TGF- $\beta$, transforming growth factor; TLR4, toll-like receptor 4 .

\section{Expression of mRNA of inflammatory factors}

A significant increase in the expression of TLR4 mRNA in GDM mothers compared to the control mothers was observed. The expression of IL- 6 and TGF- $\beta$ did not increase significantly in the GDM group (Fig. 1). We noticed an increase in the expression of mRNA of monocyte-macrophage markers, i.e., CD86, CD14 and EMR-1 in the placenta of GDM mothers. The mRNA expression of CCL2 was increased significantly in GDM mothers compared to the control mothers (Fig. 2). As regards T-cells, we observed an increase in the expression TCR $\alpha$ and GATA-3 (Fig. 3). Finally, a concomitant increase of leptin and adiponectin mRNA was observed in GDM mothers compared to the control ones (Fig. 4).

\section{Discussion}

The aim of our study was to elucidate, by RT-PCR, the placental expression of mRNA encoding for IL-6, TLR-4, TGF- $\beta$, CD68, CD14, EMR-1, CCL2, TCR- $\alpha$, T-bet, GATA-3, leptin and adiponectin in women with GDM in order to better understand the physiopathology and its repercussions in fetal macrosomia. The results of our study demonstrate that, in the placenta of GDM women, there is an installation of an inflammatory status which may be involved in the incidence of macrosomia.

In this study, the GDM women were hyperinsulinemic and hyperglycemic reflecting a decrease in insulin sensitivity in these individuals. Hyperinsulinemia could be responsible for high frequency of hyperglycemic accidents in the newborns. However, other factors like IGF-1 and
IGF-2 might also be involved in this pathology as we have previously demonstrated (Grissa et al. 2010). It has been proposed that increased fetal birth weight of newborn infants is a consequence of gestational diabetes, and it is essentially subsequent to insulin-resistance in these women (Ozuguz et al. 2011). Our results suggest that the GDM mothers were having decreased insulin sensitivity, as evidenced by their hyperglycemic and hyperinsulinemic state. The GDM mother's glucose, after its passage via the placenta, may trigger insulin release from the fetal pancreas, thus producing fetal hyperinsulinemia (Catalano et al. 1999). The glucose is not the only cause of macrosomia. Indeed, there exist correlations between maternal levels of amino-acids, triglycerides and fatty acids, and birth weight. These substrates go across the placenta and may modulate insulin secretion, insulin sensitivity and increase fetal growth (Grissa et al. 2010).

Many studies have demonstrated that there exists an inflammatory state in the placenta during diabetic pregnancy (Radaelli et al. 2003; Atègbo et al. 2006; Khan et al. 2006; Enquobahrie et al. 2009; Karen et al. 2010). In this study, we tried to shed light on the implications of different inflammatory markers. Our results show a significant increase in TLR-4 mRNA expression in GDM placenta, suggesting an increase in inflammation. Li et al. revealed that TLR- 4 induced a pro-inflammatory response and increased the risk of premature delivery (Li et al. 2010). Lin et al. conducted a study on non-obese diabetic mice and have shown a high expression of TLR- 4 in the placenta of mice that may induce inflammation and increase the risk of premature birth. In fact, TLR-4 controls several aspects of both innate and adaptive immune responses (Lin et al. 2010). Once activated, TLR-4 is capable of inducing the production of many pro-

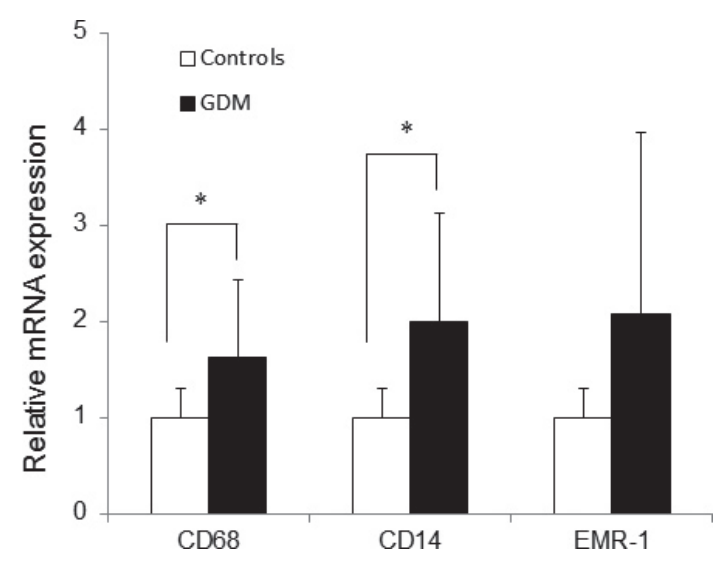

Figure 2. CD68, CD14 and EMR-1 mRNA expression in GDM placenta in comparison to control group. mRNA expression by RTqPCR was assessed as described in Materials and Methods. $n=60$ gestational diabetic mothers and macrosomic babies, ${ }^{*} p<0.05$. CD, cluster of differentiation; EMR-1, mucin-like hormone receptor 1. 


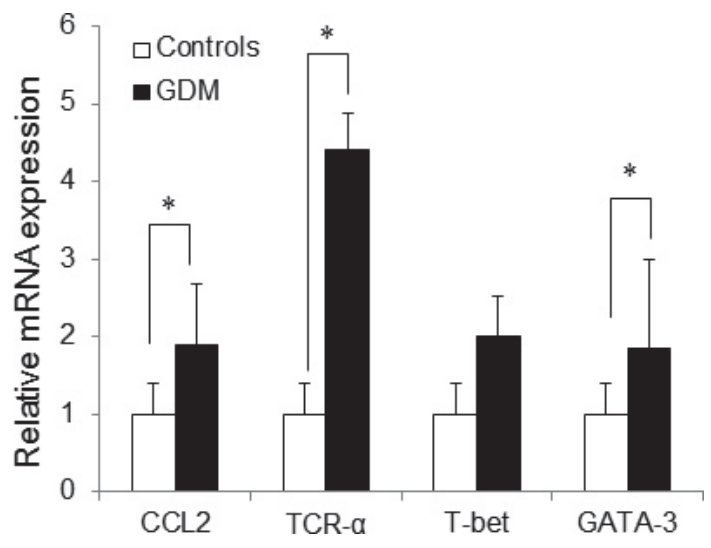

Figure 3. CCL2, TCR- $\alpha$, T-bet and GATA-3 mRNA expression in GDM placenta in comparison to control group. mRNA expression by RT-qPCR was assessed as described in Materials and Methods. $n=60$ gestational diabetic mothers and macrosomic babies, ${ }^{*} p<0.05$. CCL2, chemokine ligand 2; T-bet, T-box expressed in T-cells; TCR- $\alpha$, T-cell receptor $\alpha$; GATA-3, GATA binding protein 3 .

inflammatory molecules such as cytokines (TNF- $\alpha$, IL-12, IL-1 $\alpha$, IL-6, IL-15 and IL-18) and chemokines.

TLR4 plays a critical role in inflammation-induced pre-term delivery. TLR forms the major family of pattern recognition receptors (PRR) that are involved in innate immunity (Li et al. 2010). Innate immune response against microorganisms at the maternal-fetal interface may have a significant role on the success of pregnancy. It has been shown that in the placenta, TLR4 are expressed on immune cells and non-immune cells as decidual cells and trophoblast. Moreover, their expression pattern varies according to the stage of pregnancy (Koga and Mor 2010).

In our study, the placental expression of IL- 6 and TGF- $\beta$ mRNA showed an increase, but not significant, in GDM group compared to the control group. This observation indicates a probable increase of the placental inflammation in diabetic women. Effectively, IL-6 is pro-inflammatory cytokine highly produced during the inflammatory process. The high placental production of IL- 6 could pass into maternal and fetal circulation and inhibit the action of insulin in sensitive tissues (Fève et al. 2006). In fact, insulin resistance correlates with the increase of TNF- $\alpha$ and IL- 6 in the blood of GDM patients (Bastard et al. 2000; Freeman et al. 2002; Esposito et al. 2003; Atègbo et al. 2006). IL-6 has been shown to be implicated in pathogenesis of type 2 diabetes and is considered as a strong predictor of insulin resistance in pregnancy (Richardson and Carpenter 2007). The increase of IL-6 mRNA expression in the placenta of GDM mothers may be playing a role in the induction of diabetes (Tsigos et al. 1997).

IL- 6 is produced by macrophages, which secrete TGF- $\beta$ in the extracellular compartment during inflammation. In fact, we have found a high expression of macrophagic markers
(CD68, CD14 and EMR-1) and TGF- $\beta$ in the GDM placenta. These data demonstrate the infiltration and accumulation of monocytes and macrophage in their placenta. In this context, it is important to note that newly required monocytes in the placenta of GDM mothers may join the syncytiotrophoblast and damage the trophoblast barrier, thus promoting cellular infiltration and placental lesions. Moreover the excess of macrophage in the placenta could contribute to the creation of a chronic inflammatory state (Garcia Lloret et al. 2000). During inflammation, T-cells are able to secrete regulatory cytokines such as TGF- $\beta$ to limit potentially harmful inflammation. Indeed, TGF- $\beta$ may, as IL-4, IL-10 and IL-13, also inhibit production of IL-1, IL-10, IL-8 and TNF- $\alpha$. In addition, TGF- $\alpha$ has the ability to induce the production of the receptor antagonist for IL-1 (IL-1ra) that opposes the activities induced by IL-1 (Cavaillon 1995).

We have also studied the infiltration of T-cells into placenta and we have observed that the expression TCR- $\alpha$ mRNA in the GDM placenta has increased. In addition, there was an increase in T-bet and GATA-3 expression which are markers of Th 1 and Th2 cells, respectively (McCracken et al. 2007). Our results show that there is an infiltration of T-cells that may again contribute to the modulation of inflammation as suggested by Dandona et al. (2005).

Th1 secretes cytokines such IL-2 and INF- $\gamma$ and controls the cell-mediated immune response. However, Th2 produces cytokines such as IL-4, IL-5 IL-10 and IL-13 and stimulate eosinophils and increases the synthesis of antibodies (Sedlik 1996). Thus, we can conclude that in gestational diabetes the balance Th1/Th2 is dominated by the Th2 phenotype. Indeed, it is well established that during pregnancy the maternal immune system is oriented to avoid the Th1 in-

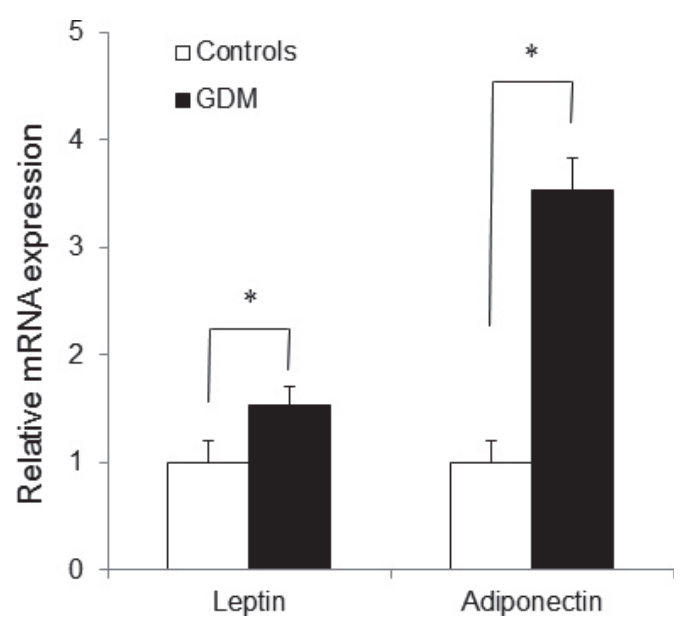

Figure 4. Leptin and adiponectin mRNA expression in GDM placenta in comparison to control group. mRNA expression by RTqPCR was assessed as described in Materials and Methods. $n=60$ gestational diabetic mothers and macrosomic babies, ${ }^{*} p<0.05$. 
flammatory response that could harm the fetus. Hence, we can state that the Th2 phenotype is protective and controls the aggravation of the inflammatory situation in the GDM (Chaouat 1999). Furthermore, insulin is an anti-inflammatory hormone (Viardot et al. 2007). In fact, the maternal hyperinsulinemia, as demonstrated in our study, might also promote the differentiation of Th0 to Th2 phenotype in the GDM placenta.

To further characterize the inflammatory profile of the GDM placenta, we evaluated the expression of leptin and adiponectin. The latter is recognized as an anti-inflammatory adipokine in many cells whereas the former is pro-inflammatory agent (Lappas et al. 2005). However, our results showed over-expression of both the adipokines. Our results are also in accordance with previous studies that have demonstrated a significant increase in placental expression of adipokines in the GDM. These observations suggest that placental adipokines are modulating the balance between pro- and anti-inflammatory statuses (Lepercq et al. 1998; Pittas et al. 2004; Ranheim et al. 2004). The exact role and function of placental adipokines are not currently understood. It has been suggested over production of leptin could alter energy metabolism lipid at this level (Lepercq et al. 2007). It is also well established that leptin stimulates placental growth (Cauzac et al. 2003; Grissa et al. 2010). Thus the increased placental leptin in the GDM could indirectly stimulate fetal growth because there is a positive correlationship between birth weight and placental weight.

It is also possible that leptin may act locally and stimulate the production of pro-inflammatory cytokines and chemoattractant protein like CCL2, and thus contributes to the activation and recruitment of macrophages in the placental tissues (Loffreda et al. 1998) and consequently to increase local inflammation (Bouloumie et al. 1998; Yamagishi et al. 2001). It has also been indicated that increased concentrations of leptin and insulin in the intrauterine environment may stimulate mitogenic pathways and would, therefore, be a potential mechanism to explain the macrosomia placenta during pregnancy diabetes (Lepercq et al. 2007).

\section{Conclusion}

A perusal of our observations suggests that the GDM is associated with expression of IL- 6 , TLR- 4 and TGF- $\beta$ mRNA, which are the markers of inflammation in the placenta. The expressions of CD68 and CD14 mRNA, which are markers of macrophagic infiltration, suggest that macrophages are recruited to the placenta during inflammation. All of these observations led us to conclude that there is an installation of inflammatory status in the maternal-fetal barrier, and the placenta. This inflammatory state may be involved in the incidence of macrosomia. However, further studies are required to elucidate the impact of inflammation in the fetus which is nutritionally regulated by the placenta.

The authors declare that they have no competing interests.

Authors' contributions. MI was in charge of the research experiments and prepared major parts of the manuscript. GO and $\mathrm{HB}$ collected and analyzed data. BA and BI conducted biochemical analyses. FM participated in interpretation of the gynecological functions. MZ conducted hormonal analyses. TZ and NAK planned and organized the study and contributed to the revisions and the final drafts of the manuscripts. All authors have read and approved the final manuscript.

Acknowledgements. We would like thank the Department of Gynecology, Farhat Hached University Hospital Sousse, Tunisia, under the direction of Professor Khairi Hédi, for the kind collaboration. We would also like to express our sincere thanks to Mrs Salwa Jemni Yakoob and Mr Taher Chakroun "Unité de recherche, étude des fonctions plaquettaires (UR06SP05) centre régionale" for their precious help.

\section{References}

Atègbo J. M., Grissa O., Yessoufou A., Hichami A., Dramane K. L., Moutairou K., Miled A., Grissa A., Jerbi M., Tabka Z., Khan N. A. (2006): Modulation of adipokines and cytokines in gestational diabetes and macrosomia. J. Clin. Endocrinol. Metab. 91, 4137-4143

http://dx.doi.org/10.1210/jc.2006-0980

Bajoria R., Sooranna S. R., Ward B. S., Chatterjee R. (2002): Prospective function of placental leptin at maternal-fetal interface. Placenta 23, 103-115 http://dx.doi.org/10.1053/plac.2001.0769

Bastard J. P., Jardel C., Bruckert E., Blondy P., Capeau J., Laville M., Vidal H., Hainque B. (2000): Elevated levels of interleukin 6 are reduced in serum and subcutaneous adipose tissue of obese women after weight loss. J. Clin. Endocrinol. Metab. 85, 3338-3342

Bellamy L., Casas J. P., Hingorani A. D., Williams D. (2009): Type 2 diabetes mellitus after gestational diabetes: a systematic review and meta-analysis. Lancet 373, 1773-1779 http://dx.doi.org/10.1016/S0140-6736(09)60731-5

Bhaumick B., Danilkewich A. D., Bala R. M. (1988): Altered placental insulin and insulin-like growth factor-I receptors in diabetes. Life Sci. 42, 1603-1614 http://dx.doi.org/10.1016/0024-3205(88)90439-0

Bouloumie A., Drexler H. C., Lafontan M., Busse R. (1998): Leptin, the product of $\mathrm{Ob}$ gene, promotes angiogenesis. Circ. Res. 83, 1059-1066 http://dx.doi.org/10.1161/01.RES.83.10.1059

Catalano P. M., Huston L., Amini S. B., Kalhan S. C. (1999): Longitudinal changes in glucose metabolism during pregnancy in obese women with normal glucose tolerance and gestational diabetes mellitus. Am. J. Obstet. Gynecol. 180, 903-916 http://dx.doi.org/10.1016/S0002-9378(99)70662-9 
Cauzac M., Czuba D., Girard J., Hauguel-de Mouzon S. (2003): Transduction of leptin growth signals in placental cells is independent of JAK-STAT activation. Placenta 24, 378-384 http://dx.doi.org/10.1053/plac.2002.0915

Cavaillon J. M. (1995): Les cytokines de l'inflammation: Cytokines et aspects biochimiques de l'inflammation. C. R. Seances Soc. Biol. Fil. 189, 531-544

Chaouat G. (1999): Cytokines, équilibre Th1/Th2 et grossesse réussie. Revue française d'allergologie et d'immunologie Clinique 39, 633-642 (in French) http://dx.doi.org/10.1016/S0335-7457(99)80011-2

Dandona P., Aljada A., Chaudhuri A., Mohanty P., Garg R. (2005): Metabolic syndrome: a comprehensive perspective based on interactions between obesity, diabetes, and inflammation. Circulation 111, 1448-1454 http://dx.doi.org/10.1161/01.CIR.0000158483.13093.9D

Enquobahrie D. A., Williams M. A., Qiu C., Meller M., Sorensen T. K. (2009): Global placental gene expression in gestational diabetes mellitus. Am. J. Obstet. Gynecol. 200, 206-213 http://dx.doi.org/10.1016/j.ajog.2008.08.022

Esposito K., Pontillo A., Di Palo C., Giugliano G., Masella M., Marfella R., Giugliano D. (2003): Effect of weight loss and lifestyle changes on vascular inflammatory markers in obese women: a randomized trial. JAMA 289, 1799-1804 http://dx.doi.org/10.1001/jama.289.14.1799

Fève B., Bastard J. P., Vidal H. (2006): Les relations entre obésité, inflammation et insulinorésistance : acquisitions récentes. C. R. Biol. 329, 587-597 http://dx.doi.org/10.1016/j.crvi.2006.03.020

Freeman D. J., Norrie J., Caslake M. J., Gaw A., Ford I., Lowe G. D., O'Reilly D. S., Packard C. J., Sattar N. (2002): West of Scotland Coronary Prevention Study: C-reactive protein is an independent predictor of risk for the development of diabetes in the West of Scotland Coronary Prevention Study. Diabetes 51, 1596-1600 http://dx.doi.org/10.2337/diabetes.51.5.1596

Galtier F., Raingeard I., Renard E., Boulot P., Bringer J. (2008): Optimizing the outcome of pregnancy in obese women: from pregestational to long-term management. Diabetes Metab. 34, 19-25 http://dx.doi.org/10.1016/j.diabet.2007.12.001

Garcia Lloret M. I., Winkler-Lowen B., Guilbert L. J. (2000): Monocytes adhering by LFA-1 to placental syncytiotrophoblasts induce local apoptosis via release of TNF-alpha. A model for hematogenous initiation of placental inflammations. J. Leukoc. Biol. 68, 903-908

Grissa O., Yessoufou A., Mrizak I., Hichami A., Amoussou-Guenou D., Grissa A., Djrolo F., Moutairou K., Miled A., Khairi H., Zaouali M., Bougmiza I., Zbidi A., Tabka Z., Khan N. A. (2010): Growth factor concentrations and their placental mRNA expression are modulated in gestational diabetes mellitus: possible interactions with macrosomia. BMC Pregnancy Childbirth 9, 10-17

Handwerger S., Freemark M. (2000): The roles of placental growth hormone and placental lactogen in the regulation of human fetal growth and development. J. Pediatr. Endocrinol. Metab. 13, 343-356 http://dx.doi.org/10.1515/JPEM.2000.13.4.343
Karen M., Yuksel O., Akyürek N., Ofluoğlu E., Cağlar K., Sahin T. T., Paşaoğlu H., Memiş L., Akyürek N., Bostanci H. (2010): Probiotic agent Saccharomyces boulardii reduces the incidence of lung injury in acute necrotizing pancreatitis induced rats. J. Surg. Res. 160, 139-144 http://dx.doi.org/10.1016/j.jss.2009.02.008

Khan N. A., Yessoufou A., Kim M., Hichami A. (2006): N-3 fatty acids modulate Th1 and Th2 dichotomy in diabetic pregnancy and macrosomia. J. Autoimmun. 26, 268-277 http://dx.doi.org/10.1016/j.jaut.2006.03.003

Kim C., Berger D. K., Chamany S (2007): Recurrence of Gestational Diabetes Mellitus-A Systemic Review. Diabetes care 30, 1314-1319

http://dx.doi.org/10.2337/dc06-2517

Kniss D. A., Shubert P. J., Zimmerman P. D., Landon M. B., Gabbe S. G. (1994): Insulinlike growth factors. Their regulation of glucose and amino acid transport in placental trophoblasts isolated from first-trimester chorionic villi. J. Reprod. Med. 39, 249-256

Koga K., Mor G. (2010): Toll-like receptors at the maternal-fetal interface in normal pregnancy and pregnancy disorders. Am. J. Reprod. Immunol. 63, 587-600 http://dx.doi.org/10.1111/j.1600-0897.2010.00848.x

Krishnaveni G. V., Hill J. C., Veena S. R., Geetha S., Jayakumar M. N., Karat C. L., Fall C. H. (2007): Gestational diabetes and the incidence of diabetes in the 5 years following the index pregnancy in South Indian women. Diabetes Res. Clin. Pract. 78, 398-404

http://dx.doi.org/10.1016/j.diabres.2007.06.002

Lappas M., Yee K., Permezel M., Rice G. E. (2005): Release and regulation of leptin, resistin and adiponectin from human placenta, fetal membranes, and maternal adipose tissue and skeletal muscle from normal and gestational diabetes mellituscomplicated pregnancies. J. Endocrinol. 186, 457-465 http://dx.doi.org/10.1677/joe.1.06227

Lee H., Jang H. C., Park H. K., Metzger B. E., Cho N. H. (2008): Prevalence of type 2 diabetes among women with a previous history of gestational diabetes mellitus. Diabetes Res. Clin. Pract. 81, 124-129 http://dx.doi.org/10.1016/j.diabres.2008.02.017

Lepercq J., Catalano P., Hauguel De Mouzon S. (2007): Leptine et grossesse : dogmes, questions et perspectives. Gynecol. Obstet. Fertil. 35, 89-95 http://dx.doi.org/10.1016/j.gyobfe.2006.12.015

Lepercq J., Cauzac M., Lahlou N., Timsit J., Girard J., Auwerx J., Hauguel De Mouzon S. (1998): Overexpression of placental leptin in diabetic pregnancies: a critical role for insulin. Diabetes $47,847-850$ http://dx.doi.org/10.2337/diabetes.47.5.847

Li L., Kang J., Lei W. (2010): Role of Toll-like receptor 4 in inflammation-induced preterm delivery. Mol. Hum. Reprod. 16, 267-272 http://dx.doi.org/10.1093/molehr/gap106

Lin Y., Xie M., Chen Y., Di J., Zeng Y. (2006): Preterm delivery induced by LPS in syngeneically impregnated BALB/c and NOD/SCID mice. J. Reprod. Immunol. 71, 87-101 http://dx.doi.org/10.1016/j.jri.2006.01.005

Loffreda S., Yang S. Q., Lin H. Z., Karp C. L., Brengman D. J., Wang A. S., Klein G. B., Bulkley C., Bao P. W., Noble M. D., Lane M. 
L., Diehl A. M. (1998): Leptin regulates proinflammatory immune responses. FASEB J. 12, 57-65

McCracken S. A., Hadfield K., Rahimi Z., Gallery E. D., Morris J. M. (2007): NF-kappaB-regulated suppression of T-bet in T cells represses Th1 immune responses in pregnancy. Eur. J. Immunol. 37, 1386-1396 http://dx.doi.org/10.1002/eji.200636322

Meller M., Qiu C., Vadachkoria S., Abetew D. F., Luthy D. A., Williams M. A. (2006): Changes in placental adipocytokine gene expression associated with gestational diabetes mellitus. Physiol. Res. 55, 501-512

Ozuguz U., Isik S., Berker D., Arduc A., Tutuncu Y., Akbaba G., Gokay F., Guler S. (2011): Gestational diabetes and subclinical inflammation: Evaluation of first year postpartum outcomes. Diabetes Res. Clin. Pract. 94, 426-433 http://dx.doi.org/10.1016/j.diabres.2011.08.024

Pittas A. G., Joseph N. A., Greenberg A. S. (2004): Adipocytokines and insulin resistance. J. Clin. Endocrinol. Metab. 89, $447-452$ http://dx.doi.org/10.1210/jc.2003-031005

Radaelli T., Varastehpour A., Catalano P., Hauguel-de Mouzon S. (2003): Gestational diabetes induces placental genes for chronic stress and inflammatory pathways. Diabetes 52, 2951-2958 http://dx.doi.org/10.2337/diabetes.52.12.2951

Ranheim T., Haugen F., Staff A. C., Braekke K., Harsem N. K., Drevon C. A. (2004): Adiponectin is reduced in gestational diabetes mellitus in normal weight women. Acta Obstet. Gynecol. Scand. 83, 341-347 http://dx.doi.org/10.1080/j.0001-6349.2004.00413.x

Reece E. A., Leguizamón G., Wiznitzer A. (2009): Gestational diabetes: the need for a common ground. Lancet 373, 1789-1797 http://dx.doi.org/10.1016/S0140-6736(09)60515-8

Richardson A. C., Carpenter M. W. (2007): Inflammatory mediators in gestational diabetes mellitus. Obstet. Gynecol. Clin. North. Am. 34, 213-224 http://dx.doi.org/10.1016/j.ogc.2007.04.001

Sedlik C. (1996): Les sous-populations de lymphocytes Thl et Th2 : caractérisation, rôle physiologique et régulation. Bull. Inst. Pasteur 94, 173-200 (in French)
http://dx.doi.org/10.1016/S0020-2452(97)86016-2

Torloni M. R., Betrán A. P., Horta B. L., Nakamura M. U., Atallah A. N., Moron A. F., Valente O. (2009): Prepregnancy BMI and the risk of gestational diabetes: a systematic review of the literature with meta-analysis. Obes. Rev. 10, 194-203 http://dx.doi.org/10.1111/j.1467-789X.2008.00541.x

Tsigos C., Papanicolaou D. A., Kyrou I., Defensor R., Mitsiadis C. S., Chrousos G. P. (1997): Dose-dependent effects of recombinant human interleukin-6 on glucose regulation. J. Clin. Endocrinol. Metab. 82, 4167-4170 http://dx.doi.org/10.1210/jcem.82.12.4422

Uzelac P. S., Li X., Lin J., Neese L. D., Lin L., Nakajima S. T., Bohler H., Lei Z. (2010): Dysregulation of leptin and testosterone production and their receptor expression in the human placenta with gestational diabetes mellitus. Placenta 31, 581-588 http://dx.doi.org/10.1016/j.placenta.2010.04.002

Viardot A., Grey S. T., Mackay F., Chisholm D. (2007): Potential anti-inflammatory role of insulin via the preferential polarization of effector T cells toward a T helper 2 phenotype. Endocrinology 148, 346-353 http://dx.doi.org/10.1210/en.2006-0686

Wroblewska-Seniuk K., Wender-Ozegowska E., Szczapa J. (2009): Long-term effects of diabetes during pregnancy on the offspring. J. Pediatr. Diabetes 10, 432-440 http://dx.doi.org/10.1111/j.1399-5448.2009.00507.x

Yamagishi S. I., Edelstein D., Du X. L., KanedaY., Guzman M., Brownlee M. (2001): Leptin induces mitochondrial superoxide production and monocyte chemoattractant protein-1 expression in aortic endothelial cells by increasing fatty acid oxidation via protein kinase A. J. Biol. Chem. 276, 25096-25100 http://dx.doi.org/10.1074/jbc.M007383200

Yogev Y., Catalano P. M. (2009): Pregnancy and obesity. Obstet. Gynecol. Clin. North. Am. 36, 285-300 http://dx.doi.org/10.1016/j.ogc.2009.03.003

Received: April 2, 2013

Final version accepted: October 2, 2013 